\title{
Pendugaan heritabilitas rill (realized heritability) dan kemajuan ge- netik produksi telur itik mojosari
}

\author{
I.M.U. Abrianto, L. Hakim, V.M.A. Nurgiartiningsih. \\ Fakultas Peternakan Universitas Brawijaya Malang \\ Corresponden author : im.unggul.abrianto@gmail.com
}

\begin{abstract}
This study aims to estimate the value of genetic parameters of realized heritability and to estimate the value of genetic progress in 10 Mojosari duck lines selected for 4 generations on the first 3 months cumulative egg production. Individual egg production records on 10 lines comprising 980 ducks with details of 108 drakes and 872 female ducks were used as research material. The results showed: 1) The realized heritability value of 3 months cumulative egg production in each duck line was moderate approaching high; 2) The response to selection of 3 months cumulative egg production selection in each duck line ranged from 0.37 to 0.48 eggs; 3) Selection on 3 months cumulative egg production characteristics could be appointed to be one of the selection criteria, because realized heritability value was moderat close to high and the response to selection was positive.
\end{abstract}

Keywords: Selection, response to selection, genetic parameters

\section{PENDAHULUAN}

Itik Mojosari telah mengalami seleksi alam dan buatan di peternakan rakyat, sehingga memiliki daya tahan baik terhadap penyakit dan sanggup mempertahankan performans dalam kondisi pakan dan manajemen jelek. Permasalahan umum itik Mojosari adalah produksi daging dan telurnya masih bervariasi, sehingga belum dimanfaatkan dengan baik untuk usaha peternakan komersial.

Perbaikan mutu genetik disamping perbaikan pakan dan manajemen diperlukan untuk memperbaiki produktivitas. Perbaikan mutu genetik, yang ditempuh melalui program pemuliaan ternak berupa seleksi dan kombinasi persilangan, menjadi cara efektif karena berdampak permanen dan diwariskan (Susanti dan Prasetyo, 2008). Seleksi bertujuan untuk memilih ternak yang diduga bermutu genetik baik sehingga berkembang biak lebih lanjut (Hardjosubroto, 1994) dan mengubah frekuensi gen pengatur sifat sehingga proporsi gen yang diinginkan meningkat (Warwick dkk., 1995).

Efektivitas program pemuliaan itik Mojosari memerlukan data parameter genetik, diantaranya heritabilitas pada sifat ekonomis penting seperti produksi telur. Nilai heritabilitas bermanfaat sebagai: 1) gambaran proporsi performans dipengaruhi oleh genetik aditif; 2) dasar program seleksi; dan 3) salah satu parameter penting menduga kemajuan genetik akibat seleksi (Warwick dkk., 1995). Heritabilitas tinggi berarti fenotip banyak dipengaruhi genetik aditif dibanding lingkungan dan akan memberikan respon seleksi tinggi bila dilakukan seleksi (Hardjosubroto, 1994). Heritabilitas lebih teliti berupa heritabilitas riil (realized heritability)), 
yang diestimasi dengan percobaan seleksi beberapa generasi dan menentukan kemajuan yang diperoleh dibandingkan dengan keunggulan tetua terpilih dalam semua generasinya. (Warwick dkk., 1995). Perbaikan mutu genetik sebaiknya menggunakan komposisi genetik lokal yang telah beradaptasi dengan kondisi lingkungan sekitar, sehingga efektif meningkatkan produktivitas dan nilai ekonomisnya (Shad et al., 2013)

Permasalahannya saat ini adalah masih sedikit referensi parameter genetik bangsa unggas lokal (Cheng et al., 1995; Norris and Ngambi, 2006) meskipun banyak literatur parameter genetik pertumbuhan dan produksi telur unggas komersial, tetapi kurang tepat diterapkan pada unggas lokal (Dana et al., 2011).

Penelitian heritabilitas produksi telur pada unggas menunjukan hasil berkisar 0,011-0,56 (Tai et al., 1989; Cheng et al., 1995; Nurgiartiningsih et al.,2002;Susanti, 2003; Nurgiartiningsih et al., 2005; Luoet al., 2007; Farzinet al., 2010; Dana et al., 2011).

Respon seleksi (R) merupakan perubahan nilai rata-rata fenotip generasi keturunan, akibat seleksi populasi tetua (Hardjosubroto, 1994). Respon seleksi produksi telur pada itik dan ayam lokal berkisar 0,6-11,2 butir (Sartika dkk., 1999; Susanti, 2003; Gunawan dan Zainuddin, 2004).

Catatan produksi telur dari program seleksi produksi telur kumulatif 3 bulan pertama selama 4 generasi pada beberapa galur itik Mojosari di Balai Pembibitan Ternak Unggul dan Hijauan Pakan Ternak (BPTU-HPT) Pelaihari Kalimantan Selatan dapat dimanfaatkan untuk menduga nilai parameter genetik heritabilitas riil dan respon seleksi. Penelitian ini bertujuan untuk menaksir nilai parameter genetik heritabilitas rill (realized heritability) produksi telur kumulatif 3 bulan dan mengestimasi nilai kemajuan genetik berupa besaran respon seleksi pada beberapa galur itik Mojosari.

\section{MATERI DAN METODE}

\section{Materi penelitian \\ 1 Data}

Data diambil dari catatan produksi telur program pemuliaan itik Mojosari selama 4 generasi tahun 2010-2015 di BPTU-HPT Pelaihari, meliputi nomor ternak, tanggal tetas dan dewasa kelamin, produksi telur harian.

Itik Mojosari berasal dari 10 galur (B, D, F, H, J, L, N, P, R, dan T) yang berjumlah 980 ekor dengan rincian jantan 108 ekor dan betina 872 ekor, terbagi 4 generasi, dengan rincian: Generasi 1: jantan 31 ekor dan betina 267 ekor ekor;Generasi 2: jantan 19 ekor dan betina 118 ekor;Generasi 3: jantan 31 ekor dan betina 267; dan Generasi 4: jantan 27 ekor dan betina 220 ekor.

Setiap generasi, itik dibagi dalam 10 kelompok perkawinan, setiap kelompok terdiri Itik Terseleksi dan Kontrol (tidak terseleksi). Gabungan Itik Terseleksi dan Itik Kontrol dalam setiap kelompok disebut dengan Itik Total. Itik Terseleksi tiap kelompok berjumlah 1 ekor pejantan dan 10 ekor betina dan sisanya Itik Kontrol. Kondisi lapang menunjukan ada kelompok tidak memiliki Itik Terseleksi sampai 10 ekor betina dan tidak memiliki Itik Kontrol, disebabkan daya tetas yang rendah dan/atau tingginya angka kematian di kelompok tersebut. Ternak generasi selanjutnya merupakan keturunan dari perkawinan antar Itik Terseleksi.

2 Seleksi

Seleksi dilakukan dengan 


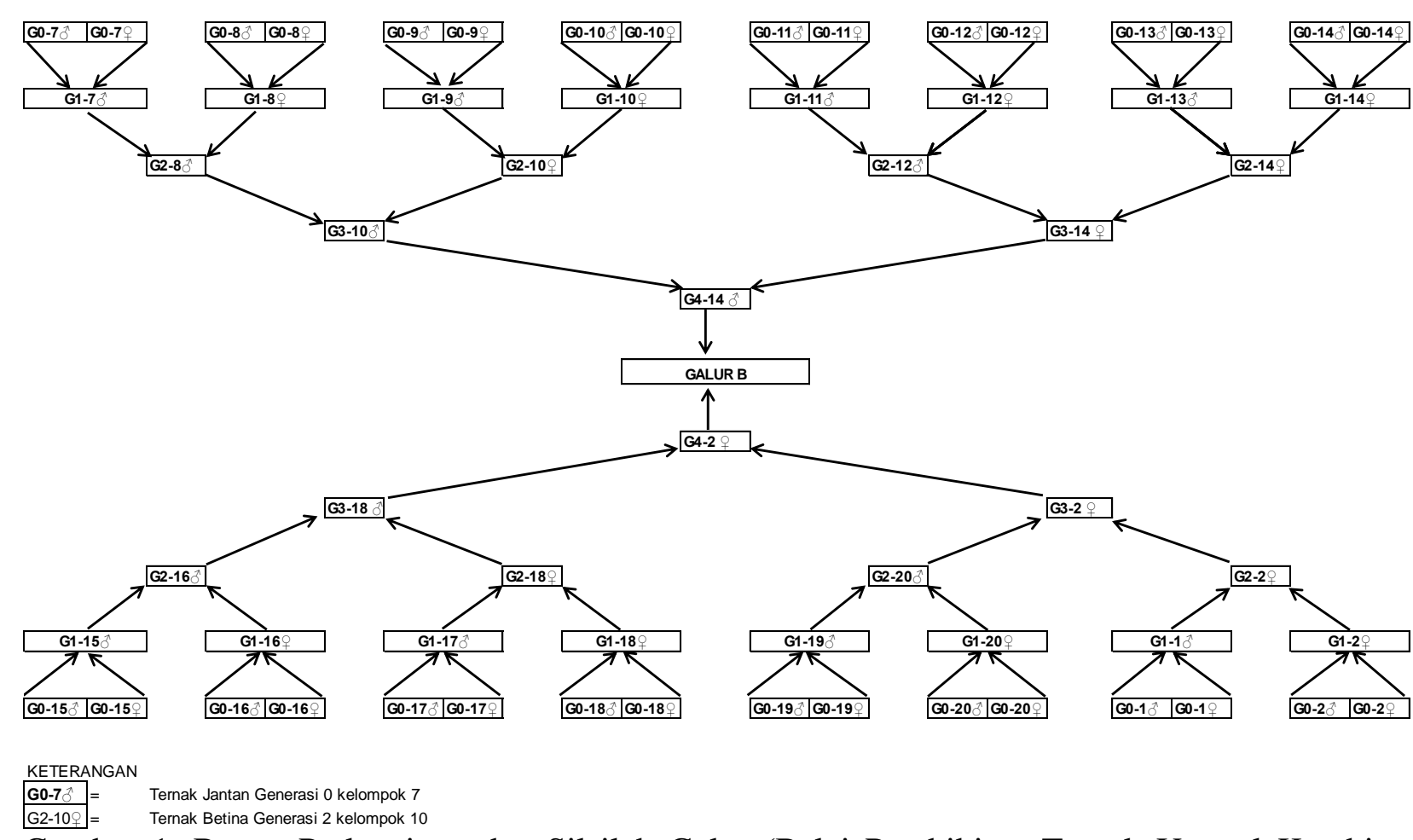

Gambar 1. Bagan Perkawinan dan Silsilah Galur (Balai Pembibitan Ternak Unggul Kambing Domba dan Itik-BPTU KDI, 2009)

Keterangan:

1 Contoh Bagan Perkawinan dan Silsilah Galur B, galur lain juga menggunakan bagan yang sama dengan kelompok yang berbeda dalam setiap generasinya.

2 Setiap galur dibentuk dari 16 perkawinan dalam kelompok di Populasi Dasar; 8 perkawinan antar kelompok di Generasi 1; 4 perkawinan antar kelompok di Generasi 2; 2 perkawinan antar kelompok di Generasi 3; dan 1 perkawinan antar kelompok di Generasi 4.

mengevaluasi catatan produksi telur kumulatif 3 bulan atau 84 hari produksi. Kriteria itik betina terseleksi adalah sesuai SNI 7559_2009 tentang Bibit Induk Itik Mojosari Muda (Badan Standardisasi Nasional, 2009) dan kemampuan tertinggi dalam produksi telur kumulatif 3 bulan tiap kelompoknya. Kriteria itik terseleksi jantan adalah memenuhi kriteria SNI 7559_2009 tentang Bibit Induk Itik Mojosari Muda dan saudara kandung dari itik betina dengan produksi telur kumulatif 3 bulan tertinggi dalam kelompoknya (BPTU KDI, 2009)

3 Bagan Perkawinan dan Silsilah Setiap Galur
Contoh bagan perkawinan dan silsilah terlampir pada Gambar 1.

\section{Metode penelitian}

Penelitian menggunakan metode observasi data primer catatan program pemuliaan beberapa galur itik Mojosari di BPTU-HPT Pelaihari.

Bagan Perkawinan dan Silsilah Galur (Gambar 1) menjadi pedoman tahapan penghitungan nilai diferensial seleksi (S), respon seleksi (R) dan heritabilitas rill (realized heritability) setiap galur.

1 Diferensial seleksi (S) dihitung dengan rumus menurut Warwick dkk.(1995): 
- Itik betina

$\mathrm{S}=\overline{\mathrm{P}}_{\mathrm{s}}-\overline{\mathrm{P}}_{\mathrm{p}}$

Keterangan

$\overline{\mathrm{P}}_{\mathrm{S}}=$ Rerata produksi telur

kumulatif 3 bulan Itik Terseleksi

$\overline{\mathrm{P}}_{\mathrm{p}}=$ Rerata produksi telur telur $\mathrm{ku}-$ mulatif 3 bulan Itik Total

- Itik jantan

$\mathrm{S}=\mathrm{i} \times \sigma_{\mathrm{p}}$

Keterangan

$\mathrm{i}=$ intensitas seleksi

$\sigma_{\mathrm{p}}=$ simpangan baku fenotif anak

betina keturunannya

- Rerata kedua tetua

$S$ rerata $=\underline{S}$ jantan $+S$ betina

2

Diferensial Seleksi (S) jantan dan betina setiap galur dihitung masing-masing kelompok sesuai Bagan Perkawinan dan Silsilah Galur, sebagai contoh nilai diferensial seleksi kumulatif Galur B dihitung mulai nilai $S$ pada pejantan kelompok G17, G1-9,..., G3-10, dan G3-18 kemudian dilanjutkan nilai $S$ pada betina kelompok G1-8, G1-10,..., G3-14, dan G3-2. Nilai diferensial seleksi pasangan jantan dan betina direrata untuk mendapatkan nilai diferensial seleksi rerata tetua, perhitungan tersebut diterapkan pada keseluruhan pasangan perkawinan untuk mendapatkan nilai diferensial kumulatif Galur B. Metode yang sama juga diterapkan pada 9 galur lain.

2 Respon seleksi(R) dihitung dengan rumus menurut Kurnianto(2009):

$\mathrm{R}=\overline{\mathrm{A}}-\overline{\mathrm{P}}$

Keterangan

$\overline{\mathrm{A}}=$ Rerata produksi telur kumulatif 3 bulan itik keturunan

$\overline{\mathrm{P}}=$ Rerata produksi telur kumulatif 3 bulan kedua tetua

Respon seleksi (R) setiap galur dihitung pada masing-masing jalur perkawinan antar kelompok sampai ke keturunan, sesuai Bagan
Perkawinan dan Silsilah Galur. Sebagai contoh pendugaan, Respon seleksi Galur B pada jalur perkawinan G1-7 $\widehat{O}$ dengan G1-8우 dengan keturunan G2-8 diketahui dengan penghitungan selisih produksi telur K3 G2-8 dengan produksi telur rerata kedua tetuanya (G1-7 dan G1-8), kemudian perhitungan dilanjutkan pada jalur perkawinan yang lain dalam generasi 1 sampai 4, untuk mendapatkan nilai respon seleksi kumulatif Galur B. Metode yang sama diterapkan untuk mendapatkan nilai respon seleksi kumulatif pada 9 Galur yang lain

3 Heritabilitas rill (realized heritability) dihitung dengan rumus menurut Warwick dkk.(1995):

$\mathrm{R}=\mathrm{h}^{2} \times \mathrm{S}$

$\mathrm{h}^{2}$ riil $=\frac{\mathrm{R}}{\mathrm{S}}=\frac{\text { kumulatif respon seleksi }}{\text { kumulatif diferensial seleksi }}$

Keterangan

$\mathrm{R}=$ Respon seleksi

$\mathrm{S}=$ Diferensial seleksi

$\mathrm{h}^{2}=$ Heritabilitas sifat yang diseleksi

Nilai heritabilitas rill (realized heritability) setiap galur diduga dengan cara membagi nilai $\mathrm{R}$ kumulatif dengan nilai $\mathrm{S}$ kumulatif

\section{HASIL DAN PEMBAHASAN}

\section{Heritabilitas rill (realized heritability)}

Hasil pendugaan nilai heritabilitas rill (realized heritability) pada masing-masing galur itik (galur B, $\mathrm{D}, \mathrm{F}, \mathrm{H}, \mathrm{J}, \mathrm{L}, \mathrm{N}, \mathrm{P}, \mathrm{R}$, dan T) berkisar antara 0,37 - 0,48 (Tabel 1).

Nilai heritabilitas rill (realized heritability) dari keseluruhan galur dikategorikan sedang atau berkisar 0,25-5,0 (Falconer dan Mackay, 1996), hasil ini sesuai dengan berbagai pendugaan heritabilitas pada beberapa sifat produksi telur unggas dengan kategori rendah-sedang (Tai et al., 1989; Cheng et al., 1995; Farzin et al., 
Tabel 1. Hasil pendugaaan nilai heritabilitas riil (realized heritability)) pada seleksi produksi telur kumulatif 3 bulan selama 4 generasi

\begin{tabular}{ccccc}
\hline \hline & & \multicolumn{3}{c}{ Seleksi produksi telur kumulatif 3 bulan pertama } \\
\cline { 3 - 5 } No & Galur & $\begin{array}{c}\text { Respon seleksi ku- } \\
\text { mulatif(butir) }\end{array}$ & $\begin{array}{c}\text { Diferensial seleksi } \\
\text { kumulatif (butir) }\end{array}$ & Heritabilitas riil \\
1 & B & 5.40 & 13.60 & 0.40 \\
2 & $\mathrm{D}$ & 4.90 & 13.37 & 0.37 \\
3 & $\mathrm{~F}$ & 5.57 & 12.91 & 0.43 \\
4 & $\mathrm{H}$ & 5.55 & 13.41 & 0.41 \\
5 & $\mathrm{~J}$ & 6.05 & 14.27 & 0.42 \\
6 & $\mathrm{~L}$ & 5.45 & 13.38 & 0.41 \\
7 & $\mathrm{~N}$ & 5.49 & 12.50 & 0.44 \\
8 & $\mathrm{P}$ & 6.23 & 14.47 & 0.43 \\
9 & $\mathrm{R}$ & 6.54 & 13.52 & 0.48 \\
10 & $\mathrm{~T}$ & 5.42 & 13.78 & 0.39 \\
\hline \hline
\end{tabular}

2010; Nurgiartiningsih et al., 2005; Nurgiartiningsih et al., 2002). Hasil tersebut lebih tinggi dibandingkan hasil pendugaan heritabilitas produksi telur 3 bulan dengan metode animal model pada itik Alabio dan Mojosari sebesar 0,235 dan 0,043 berturut-turut (Susanti, 2003).

Pendugaan nilai heritabilitas menghasilkan hasil yang bervariatif, karena nilai heritabilitas dipengaruhi beberapa faktor diantaranya: periode pengambilan data, bangsa ternak, metode pendugaan, populasi dan jumlah data (Kurnianto, 2009).

Kelemahan dari pendugaan nilai heritabilitas riil adalah nilai dari tanggapan seleksi tidak selalu konstan apabila dilakukan ulangan pada populasi sama, sehingga nilai yang diperoleh seolah hanya berlaku untuk populasi tersebut, membutuhkan biaya mahal dan waktu beberapa generasi (Hardjosubroto, 1994). Kelemahan lain, perbedaan waktu pengambilan data antara ternak tetua dan keturunannya memungkinkan terjadi perubahan lingkungan seperti iklim, pakan, penyakit, dll (Kurnianto, 2009).

Seleksi pada sifat produksi telur kumulatif 3 bulan bisa dipilih menjadi salah satu kriteria seleksi, karena nilai heritabilitas dari semua galur berkisar 0,37-0,48 atau kriteria sedang, bahkan beberapa galur mendekati kriteria tinggi. Seleksi sifat dengan nilai pewarisan tinggi diharapkan menghasilkan respon seleksi yang juga tinggi.

Nilai heritabilitas tinggi juga menunjukkan rendahnya ragam lingkungan, sejalan dengan manajemen pemeliharaan yang baku di BPTU-HPT Pelaihari sehingga pengaruh dari keragaman lingkungan terhadap performans itik dapat diminimalkan.

\section{Respon seleksi (R)}

Pendugaan respon seleksi (R) pada masing-masing galur itik berkisar antara 4,9-6,5 butir (Tabel 1).

Respon seleksi pada rerata semua galur lebih tinggi dibandingkan 
itik Alabio dan Mojosari yang diseleksi berdasarkan produksi telur 6 bulan dengan hasil 3,8 dan 0,6 butir berturutturut (Susanti, 2003), namun masih dibawah ayam yang mencapai 9,43 butir (Sartika dkk., 1999) dan 11,2 butir (Gunawan dan Zainuddin, 2004) pada sifat produksi telur 6 bulan.

Respon seleksi yang bernilai positif dengan rerata 5,66 butir dari semua galur menandakan populasi itik belum kehilangan ragam genetik dan ragam fenotifnya yang ditandai dengan semakin menurunnya respon seleksi sampai kearah nol (Hardjosubroto, 1994).

Respon seleksi atau kenaikan mutu genetik ternak $(\Delta \mathrm{G})$ berupa keunggulan genetik dari ternak yang terpilih sebagai tetua pada generasi berikutnya dibandingkan dengan rerata populasi awal. Beberapa cara dalam memaksimalkan kemajuan genetik diantaranya: 1) memaksimalkan diferensial seleksi berupa perbedaan performans antara ternak terseleksi dengan populasinya atau memaksimalkan nilai intensitas seleksi dengan cara mengetatkan proporsi ternak terpilih, 2) meningkatkan nilai heritabilitas, dengan cara meminimalkan ragam lingkungan atau membakukan manajemen lingkungan dan 3) menjaga keragaman genetik sifat terpilih (Warwick, dkk, 1995).

\section{KESIMPULAN}

1 Pendugaan nilai heritabilitas rill ( $\mathrm{re}$ alized heritability) produksi telur kumulatif 3 bulan pada masingmasing galur itik kriteria sedang mendekati tinggi;

2 Kisaran pendugaan respon seleksi produksi telur kumulatif 3 bulan pada masing-masing galur itik sebesar 4,9-6,5 butir atau bernilai positif;
3 Seleksi pada sifat produksi telur kumulatif 3 bulan bisa dipilih menjadi salah satu kriteria seleksi, karena nilai heritabilitas dari semua galur berkriteria sedang mendekati tinggi dan respon seleksi dari keseluruhan galur bernilai positif.

\section{DAFTAR PUSTAKA}

Badan Standardisasi Nasional. 2009. SNI 75592009 Bibit Induk Itik Mojosari Muda, Jakarta.

Balai Pembibitan Ternak Unggul Kambing Domba dan Itik (BPTU KDI). 2009. Program Pemuliaan Ternak Itik, Kerjasama Fakultas Peternakan Universitas Gadjah Mada dengan Balai Pembibitan Ternak Unggul Kambing Domba dan Itik. Pelaihari.

Cheng, Y.S., R. Rouvier, J.P. Poivey dan C. Tai. 1995. Genetic parameters of body weight, egg production and shell quality traits in the Brown Tsaiya laying duck, Genet Sel Evol. 27: 459472.

Dana, N., E.H.v Waaij dan J.A.M.v Arendonk. 2011. Genetic and phenotypic parameter estimates for body weights and egg production in Horro chicken of Ethiopia, Trop Anim Health Prod. 43:21-28.

Falconer, D.S. dan T.F.C. Mackay. 1996. Introduction to Quantitatif Genetics, $4^{\text {th }}$ edition. John Willey and Sons Inc. New York.

Farzin, N., R.V. Torshizi, N.E.J. Kashan dan A. Gerami. 2010. Estimates of genetic and phenotypic correlations between monthly and cumulative egg productions in a commercial broiler female line, Global Veterinaria. 5 (3): 164-167. 
Gunawan,B dan D. Zainuddin. 2004. Seleksi Generasi Kelima (G5) untuk Produksi Telur Tinggi dan Stabil dengan Ciri Fenotipik Khas Produksi. Seminar Nasional Teknologi Peternakan dan Veteriner. Balai Penelitian Ternak Bogor.

Hardjosubroto, W. 1994. Aplikasi Pemuliabiakan Ternak di Lapangan, Grassindo. Jakarta.

Kurnianto, E. 2009. Pemuliaan Ternak, Graha Ilmu. Yogyakarta.

Luo, P.Y., R.Q. Yang dan N. Yang. 2007. Estimation of genetic parameters for cumulative egg numbers in a broiler dam line by using a random regression model, Poultry Science 86: 30-36.

Nurgiartiningsih V.M.A., N. Mielenz, R. Preisinger, M. Schmutz dan L. Schüler. 2002. Genetic parameters for egg production and egg weight of laying hens housed in single and group cages. Arch. Tierz., Dummerstorf. 45 (5): 501-508

Nurgiartiningsih, V.M.A., N. Mielenz, R. Preisinger, M. Schmutz dan L. Schüler. 2005. Heritabilities and genetic correlations for monthly egg production and egg weight of White Leghorn hens estimated based on hen-housed and survivor production. Arch.Geflügelk. 69 (3). S: 98102.

Norris, D dan J.W, Ngambi. 2006. Genetic parameter estimates for body weight in local Venda chickens, Trop. Anim. Health Prod. 38: 605-609.

Sartika T., B. Gunawan dan Murtiyeni. 1999. Seleksi generasi pertama (G1) untuk mengurangi sifat mengeram dan meningkatkan produksi telur ayam lokal.
Seminar Nasional Peternakan dan Veteriner 1999. Balai Penelitian Ternak Bogor

Shad, A.G.K., A.M. Zalani dan J. Nasr. 2013. Estimation of genetic parameters, inbreeding trend and its effect production and reproduction traits of native fowl in fars province. Pakistan Journal of Biological Science. 16 (12): 598-600.

Susanti T. 2003. Strategi Pembibitan Itik Alabio dan Mojosari, Tesis. Program Pasca Sarjana. Institut Pertanian Bogor. Bogor.

Susanti, T. dan L.H. Prasetyo. 2008. Pendugaan parameter genetik sifat-sifat produksi telur itik alabio, Prosiding Seminar Nasional Teknologi Peternakan dan Veteriner. Hlm. 588-610. Bogor.

Tai, C., R. Rouvier dan J.P.Poive. 1989. Genetic parameters of some growth and egg production traits in laying Brown Tsaiya (Anas platyrynchos), Genet. Sel.Evol. 21: 377-384.

Warwick, E.J., J.M. Astuti, dan W. Hardjosubroto. 1995. PemuliaanTernak, Gadjah Mada University Press. Yogyakarta. 